Foster. T., Gillespie, K. \& McClelland, R. (1997) Menta disorders and suicide in Northern Ireland. British Journal of Psychiatry, 170, 447-452.

HAWTON, K. (1998) A national target for reducing suicide. British Medical Journal, 317, 156-157.

-. FAGG, J., Simkin, S., et al (1997) Trends in deliberate self-harm in Oxford. Implications for clinical services and the prevention of suicide. 1985-1995. British Journal of Psychiatry. 171. 556-560.

IsACSSON, G., BERGMAN, V. \& RICH, C. L. (1996) Epidemiological data suggest antidepressants reduce suicide risk among depressives. Joumal of Affective Disorders, 41, 1-8.

Jenkins, R., Bebbington, P., Brugha, T. S., et al (1998) British psychiatric morbidity survey. British Journal of Psychiatry, 173, 4-7.

KELLY, C., WEIR, J., RAFFERTY, T., et al (1998) Deliberate selfpoisoning presenting at Craigavon Area Hospital 19761996: relationship to drug prescribing. Proceedings of the Annual Meeting of the Royal College of Psychiatrists, pp. 45-46. London: Royal College of Psychiatrists.

Olrson, M., Marcus, S., Pincus, H., et al (1998) Antidepressant prescribing practices of outpatient psychiatrists. Archives of General Psychiatry. 63. 310-316.

OYDVIN, K. \& Kristinnson, A. (1991) Guidelines for DDD. Oslo: World Health Organization Collaborating Centre for Drug Statistics Methodology.
PAYKel, E. \& PRIEST, R. (1992) Recognition and management of depression in general practice: consensus statement. Brttish Medical Journal, S06. 1198-1202.

RAFFERTY, T., MCGAVOCK, H. \& WILSON-DAVIS, K. (1997) Temporal trends in drug use in one UK region, revealed by chemical group matching. Pharmacoepidemiology and Drug Safety, 6, 93-100.

Rose, G. (1993) Mental disorder and the strategles of prevention. Psychological Medicine, 23, 553-555.

RUTZ, W., VAN KNORRING, L. \& WALINDER, J. (1989) Frequency of suicide on Gotland after systematic postgraduate education of general practitioners. Acta Psychiatrica Scandinavica, 80, 151-154.

*Christopher B. Kelly, Consultant Psychiatrist, and Thèrèse Rafferty, Reserach Associate, Drug Utilisation Research Unit, The Queen's University of Belfast, Whitla Medical Building, 97 Lisburn Road, Belfast BT9 7BL

*Correspondence

\title{
Management of psychiatric in-patient violence in the Anglia region
}

\author{
Implications for record-keөping, staff training and victim \\ support
}

\author{
J. H. Dowson, J. Butler and O. Williams
}

\begin{abstract}
Aims and method A total of 384 incidents of violence against the person (six 'serious' and 378 'mild'), by adult in-patients in general psychiatric units (GPUs) and learning disability units (LDUs) in 10 National Health Senvice trusts in the Anglia region, were evaluated by intenviews with staff and examination of records. Results The findings, when compared with standards derived from previous recommendations, showed deficiencles in the documentation of incidents (there was no satisfactory written record of physical restraint for $97 \%$ of incidents in GPUs and $85 \%$ in LDUs).
\end{abstract}

in the training of staff in 'control and restraint' procedures if two or more staff were involved in physical restraint, for $3 \%$ of incidents in GPUs and $100 \%$ in LDUs, the staff had recelved no training within the previous 12 months) and in policies for victim support (there was no written pollcy that included procedures for victim support in relation to $84 \%$ of incidents in GPUs and $\mathbf{4 4 \%}$ in LDUs).

Clinical implications Trusts should consider reviewing their policies on the prevention and management of violence, particularty in relation to staff training. 
The management of 'routine' violence in psychiatric services, particularly in in-patient units, continues to place severe demands on staff, especially the nursing staff.

The present study evaluated aspects of the management of reported incidents of violence that involved physical aggression to others, in adult psychiatric in-patient units (GPUs) and learning disability in-patient units (LDUs), in the Anglia region. Information about each incident was obtained from records and from interviews with staff involved. The management of each incident then was evaluated by comparing the findings with seven standards derived from previous recommendations.

The aim of this study was to improve the management of incidents involving physical violence to others by assisting the review of unit policies.

\section{The study}

The study evaluated incidents involving either 'mild' or 'serious' injury as a result of patients' aggression, using the following definition of physical aggression: action (other than verbalisation) intended to cause pain, bodily harm or death upon another (Kaye et al, 1988). 'Mild' injury to others was defined as painful blows, bruises, sprains, welts, attempted strangulation, etc. and 'serious' injury as fracture, loss of teeth. deep cuts, loss of consciousness, rape, etc. (Kaye et al, 1988). This classification involves some judgement, so that, for example, a serious incident of attempted strangulation would be classed as a 'serious injury'. In the present study, all such incidents involving 'mild' or 'serious' injury that were notified were evaluated, including those that occurred during a control and restraint' procedure. Each 'incident' involved violence by a specified patient to one or more victims.

Ten National Health Service trusts in the Anglia Reglon, responsible for units on 15 sites, agreed to participate. Units approached were either general adult GPUs for patients aged 1665 years or adult LDUs. Units that usually lacked 24-hour staffing by qualified nurses were excluded.

For each site a 'link' person was identified who regularly notified the researcher of relevant incidents: over a five-month period for GPUs and a two-month period for LDUs. Staff involved in each incident were then contacted by telephone or in person and a semi-structured interview was given by the researcher to evaluate seven standards that had been identified from previous recommendations (Table 1) (Powell et al, 1994; Walker \& Siefert, 1994; Atakan, 1995; Mortimer, 1995). At a subsequent visit, medical and nursing notes, prescription sheets, ward reports and other relevant documentation were examined.

\section{Findings}

In relation to 106 beds in locked ('secure') units and 725 other beds in GPUs, 301 incidents of physical violence by 133 patients (78 men and 55 women) were reported that resulted in either

Table 1. Performance of general psychiatric in-patient units and learning disability in-patient units in 10 National Health Service Trusts in the Anglia region, in relation to standards of professional practice for the management of incidents of physical violence by patients

Standard of profeastonal practice

Satisfactory written record of physical restraint

Staff should have recelved training within the previous twelve months if two or more are involved in physical restraint

Physical restraint is achleved without injury to the patient

Physical restraint is achieved without injury to staff

Avallability of a written policy for the management of violent incidents

All staff involved in physical restraint procedure should be aware of any relevant hospltal pollcles

Avallability of a written policy relating to management of violent incidents which includes procedures for victim support

$n=$ number of incidents for which relevant data were obtained, l.e. It varied in relation to the standards evaluated because missing data varied between the standards.
Number of Incidents and percentoge of total incidents when stafl were judged to hove achloved the standard

General Leaming poychlatric units discablity units

$5(3 \%) n=169 \quad 6 \quad(15 \%) n=39$

$37(27 \%) n=137 \quad 0 \quad$ (0\%) $n=30$

$156(93 \%) n=167 \quad 38(100 \%) n=38$

$101(60 \%) n=168 \quad 26 \quad(67 \%) n=39$

$286(98 \%) n=292 \quad 79(96 \%) n=82$

$27(56 \%) n=48 \quad 12$ (67\%) $n=18$

$46(16 \%) n=288 \quad 62(76 \%) n=82$ 
'mild' or 'serious' injury to 359 victims. Eightysix patients were involved in only one incident whereas 18 patients were involved in four or more incidents. The effects of these incidents of violence on 353 of the 359 victims (185 men and 168 women), for whom details of injury were known, were evaluated. Most of the victims suffered 'mild' injury and did not recelve any medical treatment: $44.2 \%(n=156)$ had no visible injury: 28\% ( $n=99)$ sustained visible injury. Minor first aid was applied to a further $15.9 \%$ ( $n=56)$ and $10.2 \%(n=36)$ sought further medical advice. Finally, six victims $(1.7 \%)$ received further medical advice for 'serious' injury, as defined above. However, subsequent information (from informal talks with hospital staff and scrutiny of nursing reports) indicated that violent incidents had been under-reported during the study period; this has been a feature of previous reports (Haller \& Deluty, 1988; Thomas et al, 1995). This appeared to reflect a failure of communication and pressure of work. Nurses were the staff group most commonly in receipt of violence, forming $68.8 \% \quad(n=247)$ of the 359 victims, whereas fellow patients were the victims in $26.5 \%(n=95)$. The remainder, $4.7 \%(n=17)$, were members of the public, medical staff and other staff. Of the 291 (of a total of 301) incidents when the time of day had been recorded, $35.2 \%$ of incidents occurred during the early (day) shift, $46.4 \%$ during the late shift and $18.4 \%$ during the night shift.

In relation to 10 'secure' beds and 61 beds in LDUs, there were 83 violent incidents involving 27 patients and 106 known victims, all with 'mild' injury. As above, most of the victims did not receive any medical treatment: $47.2 \%(n=50)$ of victims had no visible injury; $32.1 \% \quad(n=34)$ sustained visible injury. Minor first aid was applied to a further $16 \%(n=17)$ and $4.7 \%(n=5)$ sought further medical advice. Fifty-two per cent ( $n=53$ ) of the 102 victims whose status was known were nurses, and $48 \%(n=49)$ were fellow patients.

When a physical restraint procedure was involved (i.e. any procedure when hands have been laid on a patient with the aim of preventing violence to others), for $68 \%$ of incidents in GPUs and $51 \%$ in LDUs for which relevant data were available, the persons directly involved in the restraint were not named in written records, and for $65 \%$ and $74 \%$, respectively, there was a failure to record roles undertaken by staff during restraint; also, for $11 \%$ and $14 \%$, respectively, there was a failure to note all injuries that had resulted. For $93 \%$ and $54 \%$, respectively, there was no indication of the duration of the restraint. Table 1 shows that this resulted in only a minority of incidents involving physical restraint. in both GPUs and LDUs, for which the standard for a written record was considered to have been achieved.
Restraint procedures were involved in 171 of the 301 incidents in the GPUs and in 39 of the 83 incidents in the LDUs. Table 1 also shows that, when staff could be interviewed, only a minority of those restraints in GPUs involving two or more staff (and none in LDUs) had been undertaken by staff who had been trained or updated in restraint techniques within the previous 12 months. In both GPUs and LDUs, 22 staff and two patients were injured during restraints when no member of staff involved had been trained or updated within the previous 12 months.

Although Table 1 shows that the majority of incidents involving physical restraint did not result in injury to patients or staff, $39 \%$ of all restraints undertaken resulted in reported injury to staff and $61 \%$ of these restraints did not meet the standard for staff training; also, of the 11 restraints that involved reported injury to patients (all 'mild'), six did not meet the standard for staff training.

All trusts had policies for the use of 'control and restraint' procedures, apart from one where re-drafting was in process. However, of the 66 restraint procedures (out of a total of 210 ) where it was possible to obtain information about all the staff involved, $41 \%$ involved some staff who were not acquainted with trust policy.

Only four out of the 15 sites had a written policy related to the management of violence that included procedures for victim support. Of the staff interviewed who had been physically assaulted, $16 \%$ of the 145 in GPUs and $24 \%$ of the 33 interviewed in LDUs considered that post-incident support for victims had been inadequate.

\section{Comment}

The recording of basic information about incidents of violence was often omitted or inadequate. Despite the burden of completing forms, a simple and reliable procedure, used routinely, would be a precaution against subsequent complaints or legal action and provide managers with the information needed to review procedures and resources (Haller \& Deluty, 1988; Atakan, 1995; Royal College of Psychiatrists. 1995). A relatively short incidents and resources' form could be used to cover physical aggression and aggression to property, as well as situations that are judged to have an increased risk of violence, such as staffing difficulties or bed occupancy of more than $100 \%$. Many of the questions could be designed as a 'tick-box' format to enable rapid completion (Royal College of Psychiatrists, 1995).

Most of the sites offered some formal 'control and restraint' training, often within a wider context. This was usually provided in house' 
and members of the hospital's own staff often had been trained as instructors. There were several different course models being used and there were differences of opinion as to which was the most suitable. The lengths of the courses varied and the categories of staff offered "control and restraint' training varied from unit to unit. Usually the initial training took 5-10 days, whereas 'training update' courses were for 1-3 days. Despite the provision for 'training update' courses, there was usually no formal procedure for ensuring regular updating. Some units, including some 'secure' units, did not meet the standard on training because 'training' updates had not occurred, although most 'secure' units were associated with a high level of initial training.

Many nurses who managed violent incidents did not have any formal training in "control and restraint' techniques. Although staff, for example those in some 'long-stay' units where the incidence of violence was low, did not always consider that they required training in the full range of techniques, some staff exposed to relatively frequent violence had not been offered any relevant training. However, it has been noted that nurses trained to respond to violence suffer relatively few injuries (Royal College of Psychiatrists, 1998). An appropriate training strategy is likely to vary considerably between different units, depending on the patients involved and the nature of the hospital site (Mortimer, 1995).

The management of violence involves a variety of professional and interpersonal skills practised in an adequately provided setting, whereas the prevention of violence is a constant priority of a psychiatric service. Furthermore, the management of violence must not be equated just with the application of physical techniques to restrain and control the patient (Powell et al, 1994; Atakan, 1995; Lodge, 1997). However, these skdlls are often an essential part of an adequate response by staff.

The present findings indicate the need for managers to review and implement policies related to routine record-keeping of incidents, staff training and victim support.

\section{Acknowledgements}

This study was supported by a grant from the Anglia Quality and Clinical Audit Committee. The authors would like to thank Ms Lorraine Allen for secretarial help.

\section{References}

ATAKAN, Z. (1995) Violence on psychiatric in-patient units: what can be done? Psychiatric Bulletin. 18. 593-595.

HALLER, R. \& DELUTY, R. (1988) Assaults on staff by psychiatric in-patients: a critical review. British Journal of Psychiatry, 162, 174-179.

KAYE, R. WOLKENFeld, F. \& MURRIL, L. M. (1988) Profile of aggression among psychiatric patients. Joumal of Nervous and Mental Disease, 176, 539-546.

LODGE, G. J. (1997) Assessing the risk of violent behaviour. Psychiatric Bulletin, 21, 703-706.

MORTIMER, A. (1995) Reducing violence on a secure ward. Psychiatric Bulletin. 19, 605-608.

Poweu, G., CAnN, W. \& Crowe, M. (1994) What events precede violent incidents in psychiatric hospitals? British Joumal of Psychiatry. 166, 107-1 12.

ROYAL COLLEGE OF PSYCHIATRISTS (1995) Strategies for the Management of Disturbed and Violent Patients in Psychiatric Units, Counc1l Report CR41. London: Royal College of Psychiatrists.

- (1998) Management of Imminent Violence, Occasional Paper OP41. London: Royal College of Psychiatrists.

Thomas C., BARTLeTt, A. \& MezeY, G. C. (1995) The extent and effects of violence among psychiatric in-patients. Psychiatric Bulletin. 19, 600-604.

WALKER, Z. \& SIEFERT, R. (1994) Violent incidents in a psychiatric intensive-care unit. British Joumal of Psychiatry, 164, 826-828.

*J. H. Dowson, Honorary Consultant Psychiatrist and University Lecturer in Psychiatry. J. Butler, Research Assistant, Department of Psychiatry. Box 189, Addenbrooke's Hospital, Cambridge CB2 209; and O. Williams, Consultant in Clinical Effectiveness, Institute of Public Health. Cambridge

*Correspondence 